\title{
ACUTE ENCEPHALOPATHY DURING NEOARSPHENAMINE TREATMENT
}

\section{A REPORT ON SIX CASES}

By W. A. YOUNG, M.R.C.S., L.R.C.P., D.T.M. \& H.

Maj., East African A.M.C.; Medical Officer in charge of Venereal Diseases Department, No. 1 General Hospital

and S. GORDON, M.R.C.P.

Maj., East African A.M.C.

The intolerance of patients to the intravenous injections of compounds of the arsphenamine group is a well-known accompaniment of the organic arsenical chemotherapy of syphilis. A representative experience is that of Ireland (1932) who found that $11 \cdot 2$ per cent of 2,100 patients under this treatment showed symptoms of intolerance to arsphenamine, and 72.5 per cent of those reacting unfavourably did so early in the course, between the first and tenth injections. He concluded that high dosage, the age of the batch of the drug, the rapidity of the injection and insufficient dilution were associated factors. Intolerance was noted twice as frequently in women as in men.

Among the less common but more serious complications of arsenotherapy is the acute cerebral syndrome known as encephalitis haemorrhagica, more recently termed acute encephalopathy. According to Harrison (1939), this severe cerebral disturbance following the injection of neoarsphenamine, has become very rare ; probably as the result of the care that has been taken in recent years over initial dosage, only eight cases were reported from 800,000 injections given to British soldiers during the war of 1914-18. Araujo was able to discover only two deaths following 308,185 injections administered at Brazilian Federal dispensaries.

\section{Nature of encephalitis}

The occurrence of encephalitic and meningo-encephalitic phenomena, apart from cases in which they are neuro-recurrences, bears a most striking relation to the administration of arsphenamine compounds. The symptoms, which usually occur between forty-eight and seventy-two hours after the second or third injection, are considered by McDonagh (1920) to be of a reactionary inflammatory nature and located in the vessels of the cortex. Milian (1926), who calls the condition " serous apoplexy," considers it a toxic phenomenon and advises that adrenaline be given intrathecally. The removal of cerebrospinal fluid or of blood and the administration of adrenaline are the most widely advised methods of treating the condition, which most regard as usually fatal. McDonagh however thought that the withdrawal of cerebrospinal fluid alone was valueless.

\section{Review of cases}

The occurrence of five fatalities from acute encephalopathy following about 10,000 injections at an East African centre perhaps demands a reconsideration of the rather heavy dosage of neoarsphenamine that we had adopted as our routine. Subject to rare individual exceptions, patients have begun their treatment with 0.6 gramme of neoarsphenamine, and this amount has been repeated at the rate of two injections each week, in addition to two weekly injections of bismuth metal, each of $0 \cdot 1$ gramme.

In our patients, all of whom were adult male Africans, a rise of temperature and injection of the conjunctivae were the only untoward phenomena frequently encountered. The feverish reaction by itself did not usually suffice to make us reduce the next dose of the drug. Reduction of the dose to 0.3 gramme or the simultaneous injection of adrenaline was; however, an occasional resort. In 1942 we encountered in a number of cases an exanthem, apparently of the nature of Milian's Ninth Day erythema (Milian).

The five cases of arsenical encephalopathy in this series which were of catastrophic type, showed a striking conformity to a pattern. Within twelve to 
forty-eight hours of the administration of the last neoarsphenamine injection, sometimes as early as the third injection, sometimes as late as the fifth, the patient had an epileptiform attack of variable intensity, became quickly comatose and died within twenty-four to forty-eight hours. The initial convulsion was a frequent, but not invariable, manifestation. One of our patients merely remained drowsy after the last injection and then lapsed into a slowly deepening coma. In another patient the convulsion was transient.

When the comatose state set in the patient appeared only semi-conscious and he made unsuccessful attempts to reply to questions and resented being touched. The pupillary and other reflexes at first remained normal. Several patients were restless and carried out numerous semi-purposeful movements, but later they lapsed into deep coma. One of them walked into the treatment room for his next injection and fell upon the floor in convulsions.

Sheppe (1930) mentions a patient who was given his third injection at 3 p.m. on the thirteenth day of treatment and, whilst chatting with his friends at 6 p.m. that evening, suddenly felt unwell and a few minutes later was unconscious and in convulsions. Sheppe's patient, who recovered, was treated with chloral hydrate per rectum, thiosulphate intravenously every six hours, adrenaline hydrochloride solution in 0.5 to 1.0 cubic centimetre doses, and hypertonic dextrose intravenously.

In our patients adrenaline seemed without effect, lumbar puncture was followed by only transitory and doubtful improvement and venesection brought no relief. In one case no less than eight cubic centimetres of adrenaline were given at the rate of one drop a minute without any apparent effect. It may be worth recording that in not one of our cases was there any evidence of coincident infection with the virus of lymphogranuloma inguinale.

Prodromal signs.-According to Jeanselme and Schulmann (1931), Milian considered that the headache of a Herxheimer reaction differs from the headache of intolerance in not yielding to adrenaline and in being less sudden in onset and cessation ; also that it is less violent and is not associated with vomiting. None of our patients had any prodromal vomiting although all may possibly have borne headaches uncomplainingly, for they were Africans. They all showed some degree of fever before the last injection was received. One on admission had a temperature of $101^{\circ} \mathrm{F}$. associated with an acute inguinal periadenitis. The Kahn reaction was positive and he gave a history of syphilis acquired either two months or fourteen months previously. The Kahn reaction became negative after the second neoarsphenamine injection had been given although there was no history of previous treatment. In another patient the temperature rose on the day after the first injection had been given and remained elevated until after the fourth injection which was accompanied by an adrenaline administration ; adrenaline was also given with his fifth injection but forty-eight hours after this he registered $100^{\circ} \mathrm{F}$. and had an epileptiform seizure. This patient's voice had been hoarse and the Kahn reaction was positive, although he maintained that the indurated genital lesion, which contained $T$. pallidum, had existed for only seven days.

In a third patient the temperature rose very slightly after the giving of the first neoarsphenamine injection and stayed between $98^{\circ}$ and $100^{\circ} \mathrm{F}$. until the onset of cerebral symptoms, which occurred less than twenty-four hours after the third injection. This man, who was of mixed race and possibly fairly reliable in the matter of history, estimated that the indurated sore had been present for one month. His throat was congested and the epitrochlear lymph glands were enlarged.

Intermediate cases.-A sixth patient with acute encephalopathy who had received continuous intravenous administration of neoarsphenamine, eventually recovered. There were also some cases of non-encephalitic nature. One patient, whose second dose had been reduced to 0.45 gramme in consequence of fever and conjunctival injection after the first injection, developed distressing pain in the chest and very rapid breathing. Nine days later when another 0.4 gramme 
was ventured upon, a rise of temperature occurred and was followed a little over a week later by jaundice. Another patient complained of body aching and developed a temperature of $104^{\circ} \mathrm{F}$. in the evening after his third injection of neoarsphenamine. A bloody diarrhoea set in and the next morning the temperature was $103^{\circ} \mathrm{F}$. ; on the third day he seemed better but later on vomited once ; early the next morning he went to his bed and died suddenly. The pathologist's post-mortem report on the cause of death was : (1) status thymico-lymphaticus, (2) acute gastro-enteritis, (3) anaphylactoid crisis.

Pathology.-Necropsies performed on our patients revealed little more than congestion or petechial haemorrhages of the brain. In one case congestion was observed throughout the alimentary canal. The following report of the case of one patient is typical. The whole brain showed oedema and numerous petechial haemorrhages. Slightly larger haemorrhages were noted in the pituitary gland. The liver showed cloudy swelling and the heart, kidney and alimentary canal showed congestion.

In comparison it may be worth recalling that Brittingham and Phinizy (1931) reported the following post-mortem findings: multiple haemorrhages into the brain and other viscera, microscopical widespread fat embolism and (strangely enough) erythrocytes resembling in every detail those of sickle cell anaemia.

We are indebted to the Director of Medical Services, East African Command, for permission to publish this paper.

\section{REFERENCES}

Araujo, Statistics for the National Academy of Medicine, Rio de Janeiro, Brazil.

Brittingham, J. W., and Phinizy, T. (1931), J. Amer. med. Ass., 96, 2021.

Friedman, C. F., and Shinefeld, M. A. (1941) Amer. J. Syph., 25, 610.

Harrison, L. W. (1939) British Encyclopaedia of Medical Practice, 11, 605.

Ireland, F. A. (1932) Amer. J. Syph., 16, 22.

Jeanselme, E., and Schulmann, E. (1931) Traité de la syphilis. Paris.

McDonagh, J. E. R. (1920) Venereal Diseases. London, p. 235.

Milian, G. (1926) Bull. Soc. franc. Derm. Syph., 33, 465.

Sheppe, W. M. (1930) W. Va. med. J., 26, 732.

Vilenchuk, A. Y. (1941) Sovetsk. vrach. zhur., 45, 35.

Voss, F. (1940) Med. Welt., 14, 843.

Young, W. A., and Gordon, S. (1942) E. Afr. med. J., 18, 302.

\section{Rehabilitation of young prostitutes : proposed experiment in the United States}

The Committee on Rehabilitation of the Baltimore Venereal Disease Council have concluded that prostitutes are divisible into three main groups. It is considered that for the girls and young women in the third group rehabilitation is possible. The social agencies are anxious to try a joint scheme divided between public and private family agencies. The Department of Public Welfare should obtain funds to maintain two homes, each to contain fifteen to twenty girls. Each home would have a matron and social service would be given by the home itself. The regular clinics could be used for treatment. Girls suffering from venereal disease will not be detained. The basis of the proposal is to help young women who are in trouble.-Venereal Disease Information, Washington, July, 1943.

\section{Control of venereal diseases in the United States}

The principles of control in venereal disease are (1) to find and then to treat infected persons until they are no longer infectious, and (2) to prevent infection by every possible means.

In 1938 there were 1,122 venereal disease clinics in the United States; today there are over 3,500. Blood tests for syphilis in 1938 numbered 3,598,000; in 1942 these totalled 20,000,000. Some 400,000 individuals attend syphilis clinics monthly. In 1942 there were 8,700,000 doses of arsenical drugs given for syphilis and 13,800,000 tablets of the sulphonamide drugs for gonorrhoea. An outstanding development is the establishment of venereal disease treatment centres. Fourteen centres are now working and twenty more were planned to open in 1943. All patients will have to remain for observation after the completion of treatment ; it is expected that the maximum period will be ten weeks. At the centre at the Hot Springs, Arkansas, over one-third of the women patients were under twenty; at another centre 60 per cent were between eighteen and nineteen, with a good number under eighteen. The majority were not prostitutes but were workers in the lowest paid occupations. Reliable estimates show that a million to a million and a half civilian workers have syphilis. Three to eight times as many people have gonorrhoea. Venereal diseases are a very great handicap to the United States war effort.Venereal Disease Information, Washington, September, 1943. 